\title{
Expression and inhibitory effects of p53-upregulated modulator of apoptosis in gallbladder carcinoma
}

\author{
ZHIDE LIU $^{1 *}$, CHENG YAN ${ }^{1 *}$, YANGYAN XIAO ${ }^{2}$, WEICHANG ZHANG ${ }^{1}$, \\ $\mathrm{LI} \mathrm{WANG}^{3}$, QINGLONG LI ${ }^{1}$ and WENWU CAI ${ }^{1}$ \\ Departments of ${ }^{1}$ General Surgery and ${ }^{2}$ Ophthalmology, The Second Xiangya Hospital, \\ Central South University, Changsha, Hunan $410011 ;{ }^{3}$ Department of Oncology, \\ Peking University Shenzhen Hospital, Shenzhen, Guangdong 518036, P.R. China
}

Received January 8, 2020; Accepted January 6, 2021

DOI: $10.3892 / 01.2021 .12495$

\begin{abstract}
The p53-upregulated modulator of apoptosis (PUMA) has been reported to be involved in various types of cancer. However, its potential biological role in gallbladder carcinoma (GBC) has not been fully elucidated. The present study aimed to determine the expression levels of PUMA and its biological effects on GBC. The mRNA and protein expression levels of PUMA in GBC tissues and cell lines were measured using reverse transcription-quantitative PCR and western blotting, respectively. The effects of PUMA overexpression on cell viability, proliferation and invasive ability were determined in vitro using the MTT, colony formation and Transwell invasion assays, respectively. The apoptotic rates were detected using the Annexin V-FITC apoptosis detection kit. Furthermore, follow-up of patients with GBC was performed to identify the association between PUMA expression levels and GBC prognosis. The results of the present study demonstrated that the expression levels of PUMA were significantly lower in the GBC tissues and cell lines compared with those in adjacent normal gallbladder tissues and normal gallbladder cells, respectively. Further experiments indicated that overexpression of PUMA inhibited the viability, proliferation and invasive ability of GBC cells compared with those in the control-transfected GBC cells. In addition, overexpression of PUMA significantly promoted apoptosis in GBC cells. Furthermore, overexpression of PUMA inhibited epithelial-mesenchymal transition, and promoted Bax upregulation and Bcl-2 downregulation compared with
\end{abstract}

Correspondence to: Dr Wenwu Cai, Department of General Surgery, The Second Xiangya Hospital, Central South University, 139 Renmin Road, Changsha, Hunan 410011, P.R. China

E-mail: caiwenwu1986@csu.edu.cn

*Contributed equally

Key words: gallbladder carcinoma, p53-upregulated modulator of apoptosis, epithelial-mesenchymal transition, Bax/Bcl-2, molecular mechanism those in the control group. Low PUMA expression levels were associated with a short overall survival time in patients with GBC. In conclusions, PUMA may act as a tumor suppressor in GBC and may serve as a potential novel treatment target for human GBC.

\section{Introduction}

Gallbladder carcinoma (GBC) was the fifth most common malignant tumor of the digestive system and the most common malignant tumor of the biliary tract worldwide in $2015(1,2)$. Early diagnosis and radical surgical resection are the most effective and preferred treatment approaches for patients with GBC, resulting in improved long-term survival $(3,4)$. However, due to the atypical early symptoms, and frequently rapid and asymptomatic progression, a large proportion of patients with GBC are likely to be diagnosed with late stage cancer; thus, resectable GBC accounts for only $15-47 \%$ of all cases $(5,6)$. The aforementioned features of GBC may account for the unsatisfactory prognosis of patients for GBC. The median survival time of patients with GBC is only $\sim 6$ months, with a 5-year survival rate of $<5 \%$ worldwide in 2019 (7). Eventually, the majority of patients with GBC succumb to metastatic disease (8).

Previous studies have reported that p53-upregulated modulator of apoptosis (PUMA) serves important roles in inducing apoptosis in both normal and tumor cells (9-11). In vitro experiments have demonstrated that PUMA induced esophageal and lung cancer cell apoptosis, and significantly attenuated the viability and proliferative ability of head and neck cancer cell lines; consistent with the in vitro results, the inhibitory effect of PUMA on the tumor growth was confirmed in nude mice in vivo (9-12). The aforementioned studies indicate that PUMA serves a crucial inhibitory role in tumor development. In addition, PUMA is associated with the progression, recurrence and metastasis and prognosis of colon and prostate cancers $(13,14)$.

However, the expression profile and potential biological roles of PUMA in patients with GBC have not been fully elucidated to date. Therefore, the current study aimed to determine the expression levels of PUMA in GBC tissues and cell lines, and to further investigate its effects in GBC pathogenesis. 


\section{Materials and methods}

Clinical specimen collection. A total of 18 paired GBC and adjacent normal gallbladder tissues were collected from patients who underwent surgical treatment between December 2016 and December 2018 in the Second Xiangya Hospital (Changsha, China), including 6 men and 12 women, with the mean age of 52 years (range, $42-68$ years) in Nevin's stage I-III (15). All patients enrolled in the present study had not undergone any treatment prior surgery. The fresh GBC and adjacent normal gallbladder tissues were stored at $-80^{\circ} \mathrm{C}$ in liquid nitrogen until RNA extraction. Written informed consent for participation and publication were obtained from all patients. Follow-up was performed after surgery until December 2019, and no cases were lost to the follow-up. This study was approved by the Research Ethics Committee of the Second Xiangya Hospital (approval no. 179 in 2017).

Cell culture. The normal gallbladder cells were obtained by primary culture of cells isolated from healthy gallbladder wall tissue, which was obtained from six patients with gallbladder polyps undergoing cholecystectomy, including three men and three women, with the mean age of 50 years (range, 44-65 years). Written informed consent for participation and publication were obtained from all patients. The gallbladder wall tissue was transferred to ice-cold $\mathrm{Ca}^{2+}$-free Hanks solution with $0.5 \mathrm{mM}$ EGTA and cut into $1-\mathrm{cm}^{2}$ fragments under sterile conditions. Subsequently, the tissue was placed on a $60-\mathrm{mm}$ culture dish and treated for $45 \mathrm{~min}$ at room temperature with $0.025 \%$ trypsin (Thermo Fisher Scientific, Inc.) in PBS containing 0.02\% EDTA-2Na. The tissue was agitated every $15 \mathrm{~min}$ using a pipette to promote the release of the cells. The gallbladder cells were collected by centrifugation at 1,200 $\mathrm{xg}$ for $5 \mathrm{~min}$ and counted in a CC-108 microcell counter (TOA Corporation).

Human GBC cell lines GBC-SD, SGC-996, NOZ and EHGB-1 obtained from the Institute of Biochemistry and Cell Biology of the Chinese Academy of Sciences. The GBC cells were cultured in Dulbecco's modified Eagle's medium (Gibco; Thermo Fisher Scientific, Inc.) containing 10\% fetal bovine serum supplemented with $100 \mathrm{U} / \mathrm{ml}$ penicillin and $100 \mathrm{U} / \mathrm{ml}$ streptomycin (Invitrogen; Thermo Fisher Scientific, Inc.) at $37^{\circ} \mathrm{C}$ with $5 \% \mathrm{CO}_{2}$.

$R N A$ extraction and reverse transcription-quantitative (RT- $q)$ $P C R$. The TRIzol ${ }^{\circledR}$ Reagent (Invitrogen; Thermo Fisher Scientific, Inc.) was used to extract RNA from clinical tissues and cell lines, which was subsequently treated with DNase I (Invitrogen; Thermo Fisher Scientific, Inc.) for purification according to the manufacturer's instructions. The miRcute miRNA First-Strand cDNA Synthesis kit (Takara Bio, Inc.) was used to perform reverse transcription according to the manufacturer's instructions. qPCR was performed using the SYBR $^{\circledR}$ Green PCR detection kit (Takara, Bio, Inc.) in a 7500 Real-Time PCR system (Applied Biosystems; Thermo Fisher Scientific, Inc.) according to the manufacturer's instructions with the following primers: PUMA forward, 5'-TGAAGA GCAAATGAGCCAAACG-3' and reverse, 5'-CAGAGCACA GGATTCACAGTCT-3'; and GAPDH forward, 5'-TGACTT CAACAGCGACACCCA-3' and reverse, 5'-CACCCTGTT
GCTGTAGCCAAA-3'. The expression levels of GAPDH were used to normalize the results and the $2^{-\Delta \Delta \mathrm{Cq}}$ method was used to calculate the relative expression levels of target gene (16).

Western blotting. Total protein was extracted from clinical tissues and cell lines using RIPA lysis buffer $(50 \mathrm{mM}$ Tris $\mathrm{pH} 8.0,120 \mathrm{mM} \mathrm{NaCl}, 0.5 \%$ sodium deoxycholate, $0.5 \%$ NP-40, 0.1\% SDS, $1 \mathrm{mM}$ EDTA, $50 \mathrm{mM} \mathrm{NaF}, 1 \mathrm{mM} \mathrm{Na}_{2} \mathrm{VO}_{4}$, $1 \mathrm{mM}$ PMSF and $2 \mu \mathrm{g} / \mathrm{ml}$ aprotinin) on ice for $30 \mathrm{~min}$. The protein concentration was determined by BCA assay, and $50 \mu \mathrm{g}$ protein/lane was separated by $10 \%$ SDS-PAGE at $120 \mathrm{~V}$ for $60 \mathrm{~min}$ and transferred to PVDF membranes. The membranes were blocked with 5\% non-fat milk in TBS (10 mM Tris pH 7.4 and $150 \mathrm{mM} \mathrm{NaCl}$ ) and $0.1 \%$ Tween-20 (TBST) at room temperature for $60 \mathrm{~min}$, followed by incubation with primary antibodies against PUMA (1:1,000; cat. no. ab33906), E-cadherin (1:10,000; cat. no. ab40772), vimentin (1:1,000; cat. no. ab92547), Bax (1:1,000; cat. no. ab32503), Bcl-2 (1:2,000; cat. no. ab182858) (all from Abcam) and $\beta$-actin (1:1,000; cat. no. A2228; Sigma-Aldrich; Merck $\mathrm{KGaA}$ ) at $4^{\circ} \mathrm{C}$ for $12 \mathrm{~h}$. Subsequently, the membranes were washed three times with TBST for $5 \mathrm{~min}$ and incubated with HRP-conjugated goat anti-rabbit $\operatorname{IgG}(1: 2,000$; cat. no. sc-2004) or anti-mouse IgG (1:2,000; cat. no. sc-2005) (both from Santa Cruz Biotechnology, Inc.) secondary antibody at $37^{\circ} \mathrm{C}$ for $60 \mathrm{~min}$. The protein bands were visualized with an enhanced chemiluminescence system (Thermo Fisher Scientific, Inc.) according to the manufacturer's instructions. The Gel Doc 2000 imaging system (Bio-Rad Laboratories, Inc.) was used for densitometric analysis of the protein bands with ImageJ software (version 1.8.0.112; National Institutes of Health) according to the manufacturer's instructions. $\beta$-actin was used as the internal control.

Plasmid generation and cell transfection. The PUMA sequence was synthesized and subcloned into the LV-BBC3 vector (22944-1) (Shanghai GeneChem Co., Ltd.). Ectopic expression of PUMA was achieved by the PUMA lentivirus transfection, and an empty vector (KL8781-1) (Shanghai GeneChem Co., Ltd.) used as a negative control. Prior to transfection, human GBC cell lines were cultured in complete medium without antibiotics for at least $24 \mathrm{~h}$. When the GBC-SD and EHGB-1 cell confluence reached $30-50 \%$, the cells were washed with 1X PBS once and transfected with the LV-BBC3 (22944-1) $\left(5 \times 10^{8} \mathrm{TU} / \mathrm{ml} ; 40 \mu \mathrm{l} ; \mathrm{MOI}, 20\right)$ and empty (KL8781-1) $\left(5 \times 10^{8} \mathrm{TU} / \mathrm{ml} ; 40 \mu \mathrm{l} ; \mathrm{MOI}, 20\right)$ vector at $37^{\circ} \mathrm{C}$ for $72 \mathrm{~h}$, in the presence of Lipofectamine ${ }^{\circledR} 2000$ (Invitrogen, Thermo Fisher Scientific, Inc.) according to the manufacturer's instructions. At $48 \mathrm{~h}$ post-transfection, the cells were harvested, and the expression levels of PUMA were determined by RT-qPCR.

MTT assay. At $48 \mathrm{~h}$ post-transfection, the cells were seeded into 96 -well plates $\left(2 \times 10^{4}\right.$ cells/well). Following culture for $4 \mathrm{~h}$ at $37^{\circ} \mathrm{C}$, the supernatant was discarded, and $150 \mu \mathrm{l}$ DMSO was added to each well. After shaking for $10 \mathrm{~min}, 100 \mu \mathrm{l}$ cell suspension was placed into another 96-well plate with $100 \mu \mathrm{l}$ DMSO solution as a control. The Cell Proliferation Reagent Kit I (MTT; Roche Applied Science) was used at $37^{\circ} \mathrm{C}$ for $4 \mathrm{~h}$ to determine the cell viability. The absorbance values were determined at $450 \mathrm{~nm}$ using a spectrophotometer (Omega Bio-Tek, Inc.). 

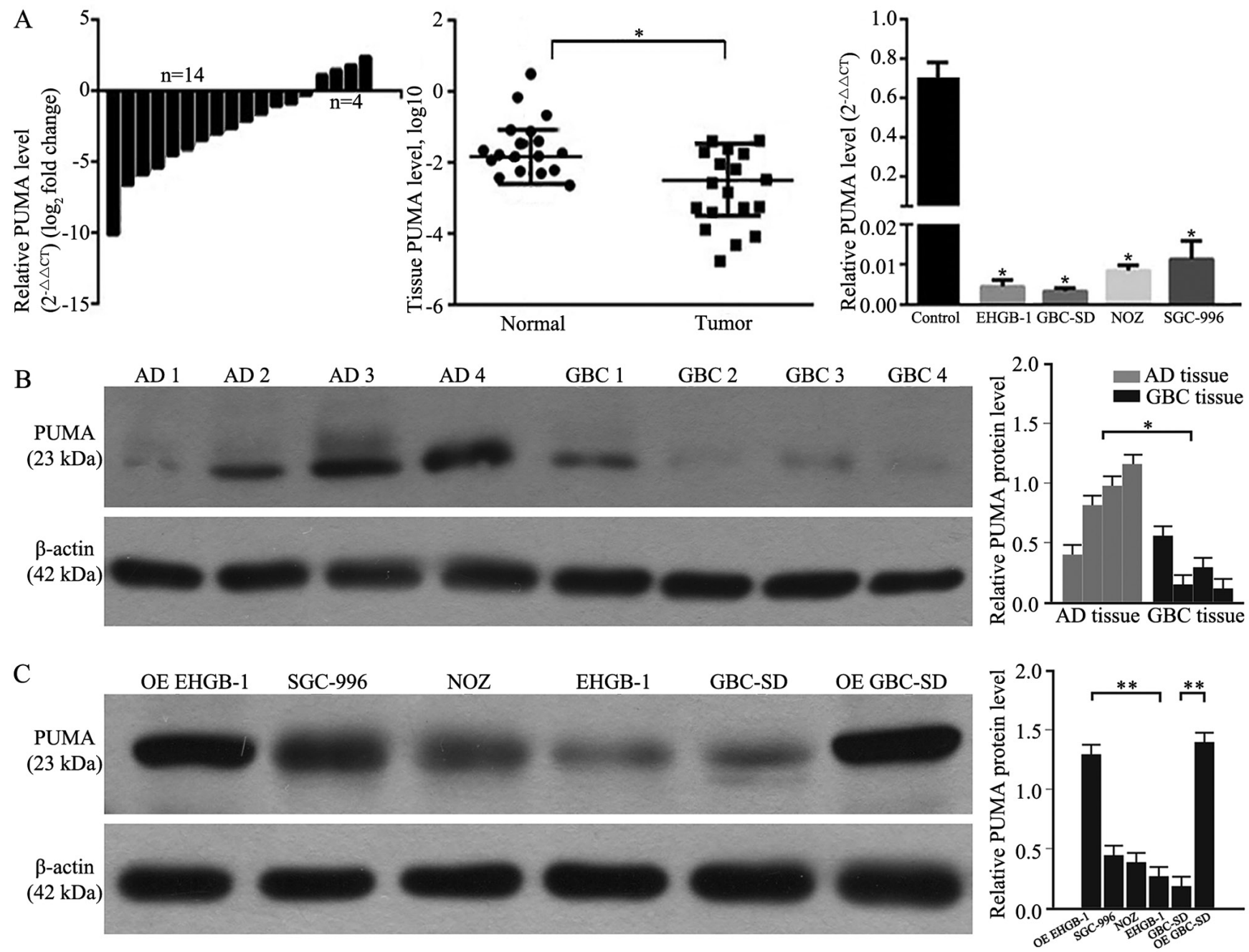

Figure 1. PUMA mRNA and protein expression levels in GBC tissues and cell lines. (A) PUMA mRNA expression levels were significantly lower in GBC tissues compared with those in adjacent tissues, and in GBC cell lines compared with those in the normal group. (B) PUMA protein expression levels in GBC tissues were significantly decreased compared with those in the adjacent tissues. (C) PUMA protein expression levels in GBC cell lines and PUMA-overexpressing EHGB-1 and GBC-SD cell lines. ${ }^{*} \mathrm{P}<0.05$ and ${ }^{* *} \mathrm{P}<0.01$ vs. normal or as indicated. PUMA, p53-upregulated modulator of apoptosis; GBC, gallbladder carcinoma; AD, adjacent.

Colony formation assay. At $48 \mathrm{~h}$ post-transfection, the cells were harvested, trypsinized and counted. A total of 500 cells/well were placed into a 6 -well plate and cultured at $37^{\circ} \mathrm{C}$. The culture medium was refreshed every 3 days. Following 14-day culture, the cells were washed with $1 \mathrm{X}$ PBS, fixed with $3.7 \%$ methanol at $37^{\circ} \mathrm{C}$ for $15 \mathrm{~min}$ and stained with $0.1 \%$ crystal violet at $37^{\circ} \mathrm{C}$ for $10 \mathrm{~min}$ (Sigma-Aldrich; Merck $\mathrm{KGaA}$ ). Visible colonies $\geq 50$ cells were manually counted using an optical microscope (Olympus Corporation).

Transwell invasion assay. The invasive ability of the cells was evaluated using an $8-\mu \mathrm{m}$ pore Transwell chamber. The upper chamber was pre-coated with Matrigel at $37^{\circ} \mathrm{C}$ overnight. At $48 \mathrm{~h}$ post-transfection, the cells $\left(1 \times 10^{5}\right)$ were suspended in serum-free DMEM and plated into the upper chamber. The lower chamber was filled with DMEM containing $10 \%$ FBS. Following 48 -h incubation at $37^{\circ} \mathrm{C}$ with $5 \% \mathrm{CO}_{2}$, the chamber was removed, and the cells remaining in the upper chamber were cleaned with cotton wool. The invasive cells were washed with $1 \mathrm{X}$ PBS, fixed with $100 \%$ methanol at $37^{\circ} \mathrm{C}$ for $30 \mathrm{~min}$ and stained with $0.1 \%$ crystal violet at $37^{\circ} \mathrm{C}$ for
20 min. Finally, images of five random fields were captured using an optical microscope (x400 magnification; Olympus Corporation) for quantification analysis. Each experiment was repeated three times.

Flow cytometry. The cells were inoculated in a 6-well plate $\left(1 \times 10^{5}\right.$ cells/well $)$ and divided into four groups: GBC-SD control, GBC-SD PUMA overexpression, EHGB-1 control and EHGB-1 PUMA overexpression. The cells were collected, washed and resuspended in PBS. The Annexin V-FITC apoptosis detection kit (Beckman Coulter, Inc., USA) was used to detect apoptotic cells with Annexin V-FITC and PI double staining according to the manufacturer's instructions. The analysis was performed using a BD FACSAria ${ }^{\mathrm{TM}}$ II flow cytometer (Becton, Dickinson and Company), and the data were analyzed using CellQuest Pro software (version 5.1; Becton, Dickinson and Company).

Statistical analysis. Data are presented as the mean \pm standard deviation. SPSS 17.0 software (SPSS, Inc.) was used for statistical analyses. The differences were analyzed using 

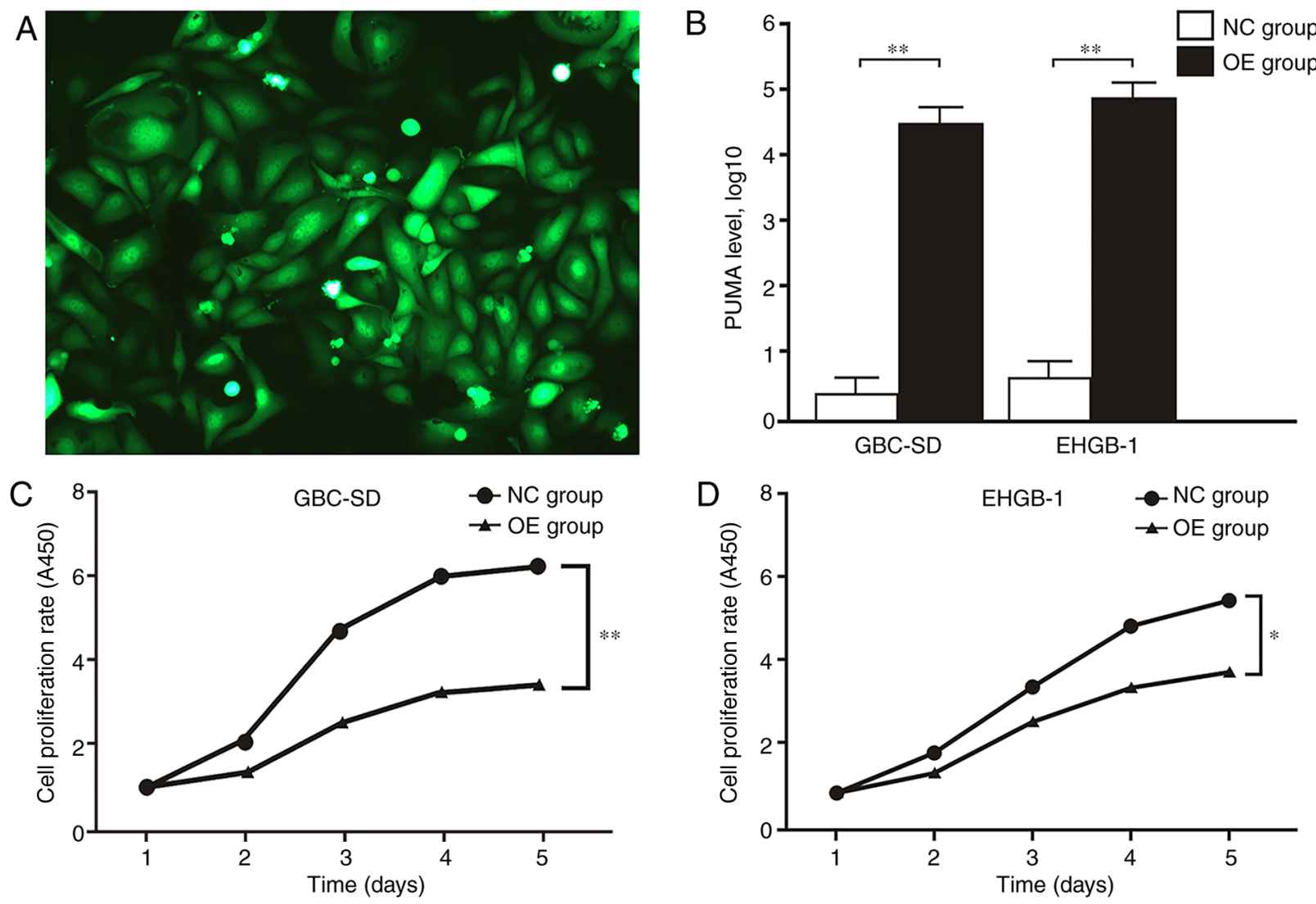

Figure 2. PUMA overexpression inhibits gallbladder carcinoma cell proliferation. (A) Fluorescence of GBC-SD cells following transfection with the LV-BBC3 vector. (B) PUMA mRNA expression were levels significantly upregulated in the GBC-SD and EHGB-1 OE groups compared with those in the corresponding NC groups. (C and D) Cell proliferation was significantly inhibited in the (C) GBC-SD and (D) EHGB-1 OE groups compared with that in the corresponding NC groups. ${ }^{*} \mathrm{P}<0.05$ and ${ }^{* *} \mathrm{P}<0.01$. PUMA, p53-upregulated modulator of apoptosis; NC, negative control; OE, PUMA overexpression.

paired-samples Student's t-test for two paired groups, independent sample Student's t-test for two independent groups and one-way ANOVA with the Bonferroni correction for multiple groups. $\mathrm{P}<0.05$ was considered to indicate a statistically significant difference.

\section{Results}

PUMA is expressed at low levels in GBC tissues and cell lines. RT-qPCR and western blotting were performed to determine the levels of PUMA expression in GBC and adjacent normal gallbladder tissues, as well as in GBC cell lines. As demonstrated in Fig. 1A and B, 77.8\% (14/18) of GBC tissues exhibited decreased mRNA expression levels of PUMA compared with those in the adjacent tissues. Compared with those in the adjacent normal gallbladder tissues, the expression levels of PUMA were significantly lower in GBC tissues. Furthermore, the expression levels of PUMA were also significantly lower in GBC cell lines compared with those in primary normal gallbladder cells. As PUMA expression levels were lower in GBC-SD and EHGB-1 cell lines compared with those in the other two cell lines, the GBC-SD and EHGB-1 cell lines were used in the subsequent experiments. Following PUMA overexpression vector transfection, the levels of PUMA protein expression were detected; as presented in Fig. 1C, the expression levels of PUMA protein were significantly higher in PUMA-overexpressing EHGB-1 and GBC-SD cells compared with those in the corresponding control groups.

Overexpression of PUMA inhibits GBC cell proliferation and invasion. MTT and colony formation assays were performed to verify the function of PUMA in GBC. The expression levels of PUMA in GBC-SD and EHGB-1 cells were upregulated by transfection with LV-BBC3 (22944-1) vector, and the empty (KL8781-1) vector was used as a negative control (Fig. 2A). As presented in Fig. 2B, PUMA mRNA expression levels were significantly upregulated in GBC-SD and EHGB-1 overexpression groups compared with those in the negative control groups. The proliferation of GBC-SD and EHGB-1 cell lines was significantly inhibited in the PUMA overexpression groups compared with that in the control groups, and the inhibitory effect appeared to become stronger with the increasing time post-transfection (Fig. 2C and D). Furthermore, the colony formation ability of the GBC-SD and EHGH-1 cells was detected by colony formation assay; as demonstrated in Fig. 3A, compared with that in the negative control group, the colony formation ability was significantly suppressed in the PUMA overexpression groups.

Transwell invasion assay was used to evaluate the effects of PUMA on the cell invasive ability in vitro. The results demonstrated that compared with those in the negative control groups, the numbers of invasive cells were significantly lower in the PUMA overexpression groups (Fig. 3B). These results 
A

GBC-SD

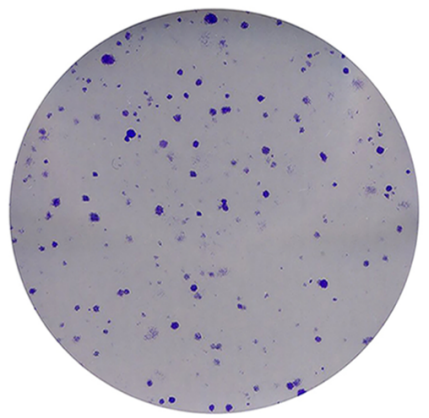

EHGB-1

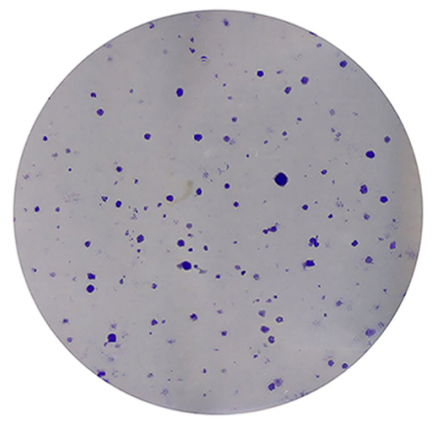

NC group

B
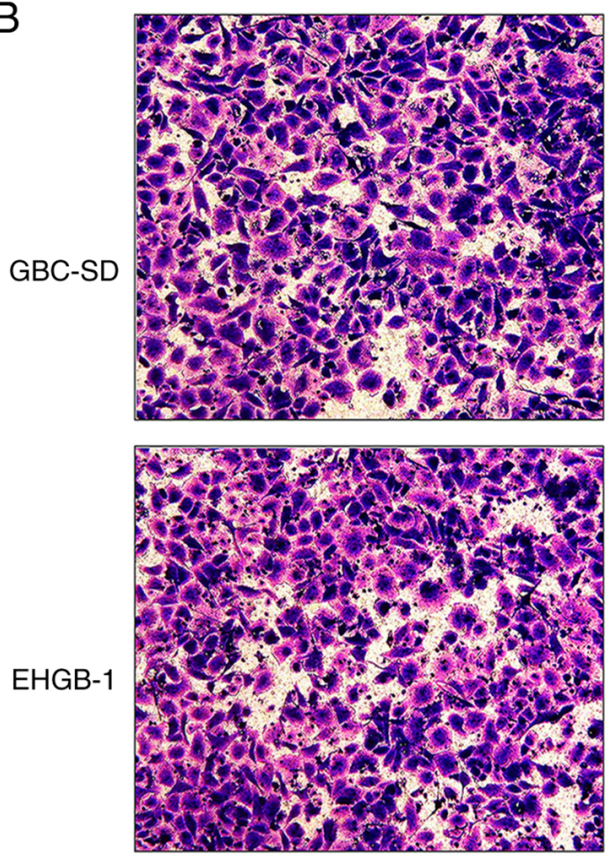

NC group
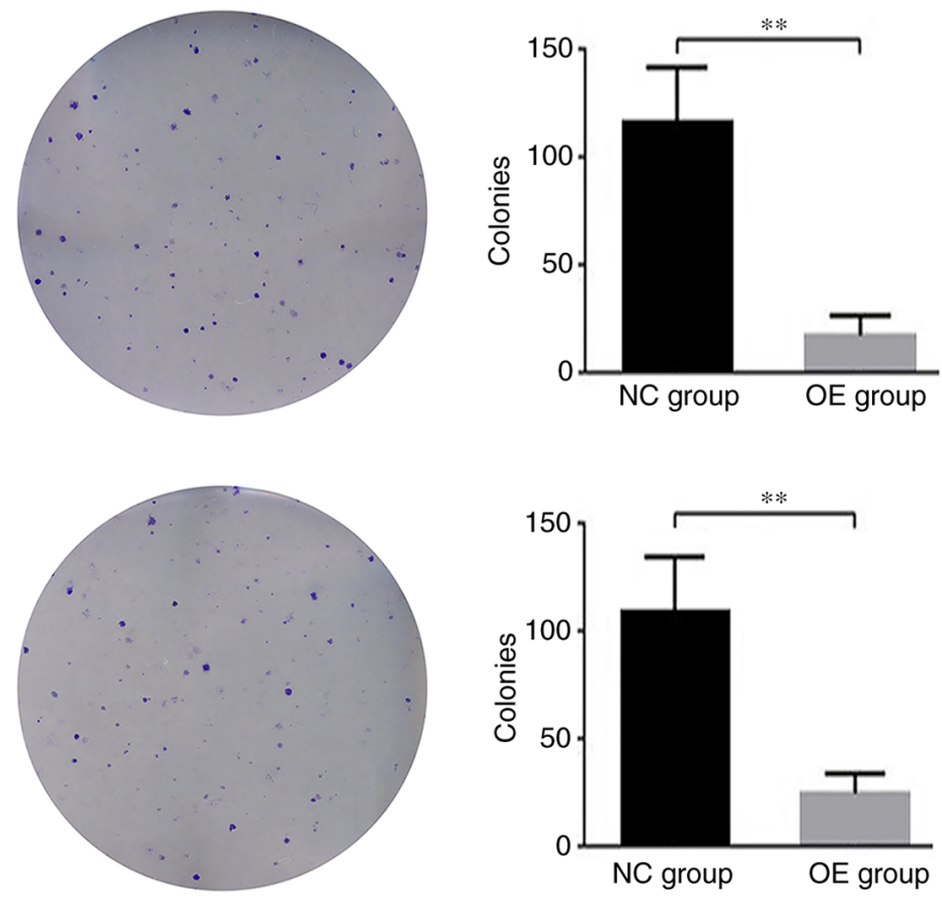

OE group
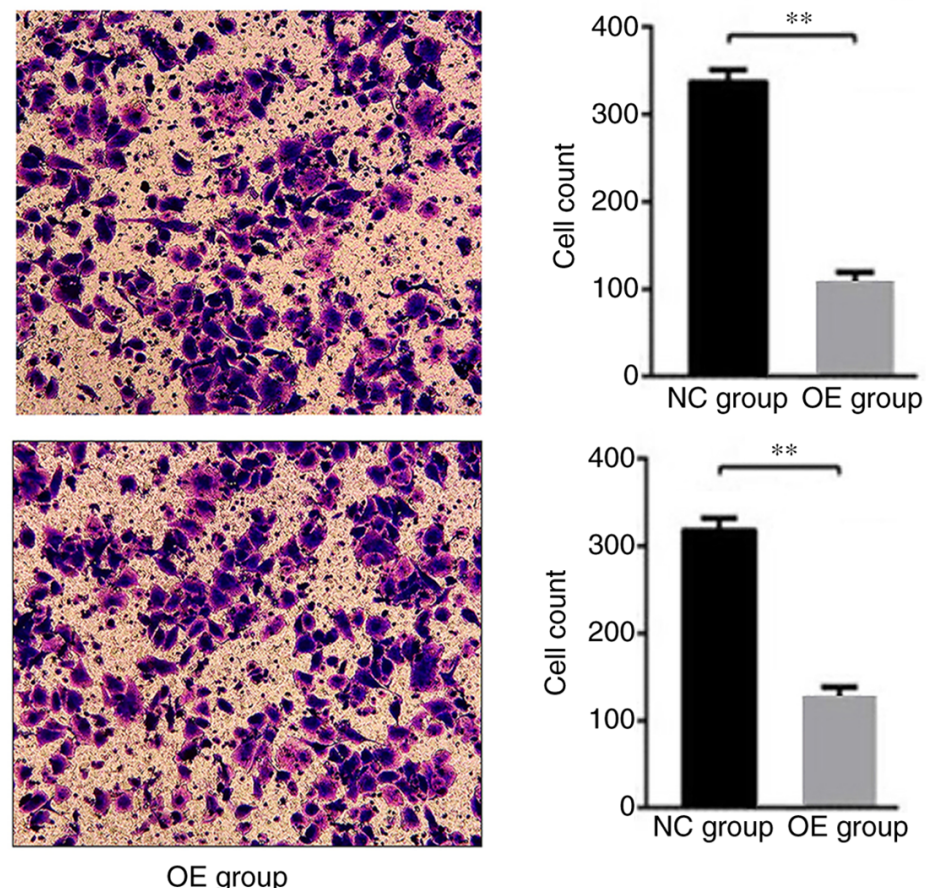

Figure 3. PUMA overexpression inhibits gallbladder carcinoma cell colony formation and invasion. (A) The colony formation and (B) invasive abilities were significantly inhibited in the GBC-SD and EHGB-1 OE groups compared with those in the corresponding NC groups. ${ }^{* *}$ P $<0.01$. PUMA, p53-upregulated modulator of apoptosis; NC, negative control; OE, PUMA overexpression.

suggested that PUMA may act as a negative regulator of the invasive ability of GBC cells.

PUMA inhibits the epithelial-mesenchymal transition (EMT), and promotes the upregulation of Bax and the downregulation $B c l-2$. As the EMT process serves a critical role in cancer cell migration and invasion, the expression levels of EMT-induced makers were detected in GBC cells. As demonstrated in Fig. 4A, the protein levels of E-cadherin were upregulated, whereas the levels of vimentin were downregulated in the PUMA overexpression groups compared with those in the negative control groups. In addition, the protein expression levels of Bax were upregulated, and the levels of $\mathrm{Bcl}-2$ were downregulated in the PUMA overexpression groups compared with those in the negative control groups (Fig. 4B). These results suggested that PUMA may regulate the $\mathrm{Bax} / \mathrm{Bcl}-2$ signaling pathway and the EMT to inhibit the invasive ability of GBC cells.

PUMA promotes apoptosis in GBC cells. Following overexpression of PUMA, the apoptotic rates of GBC-SD and 
A

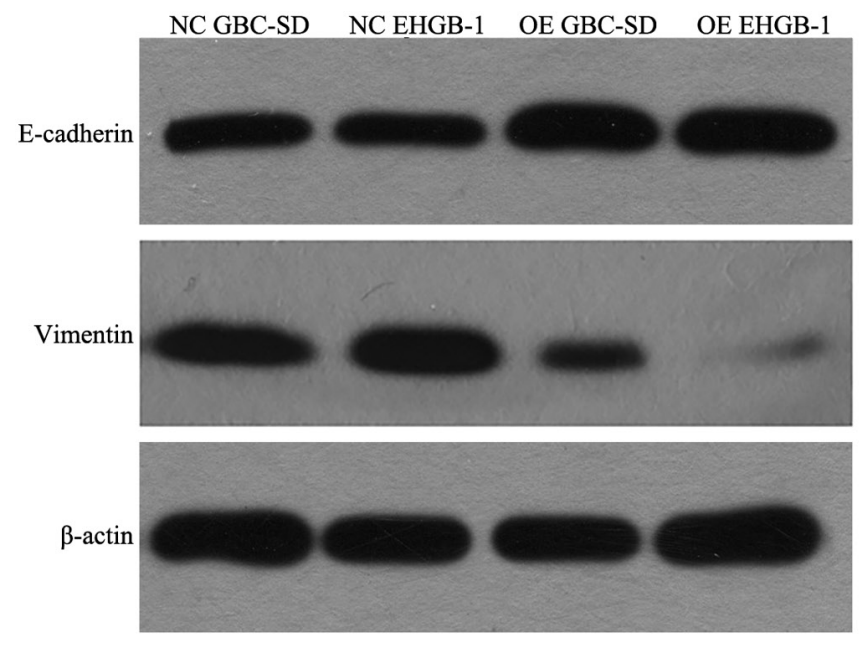

B

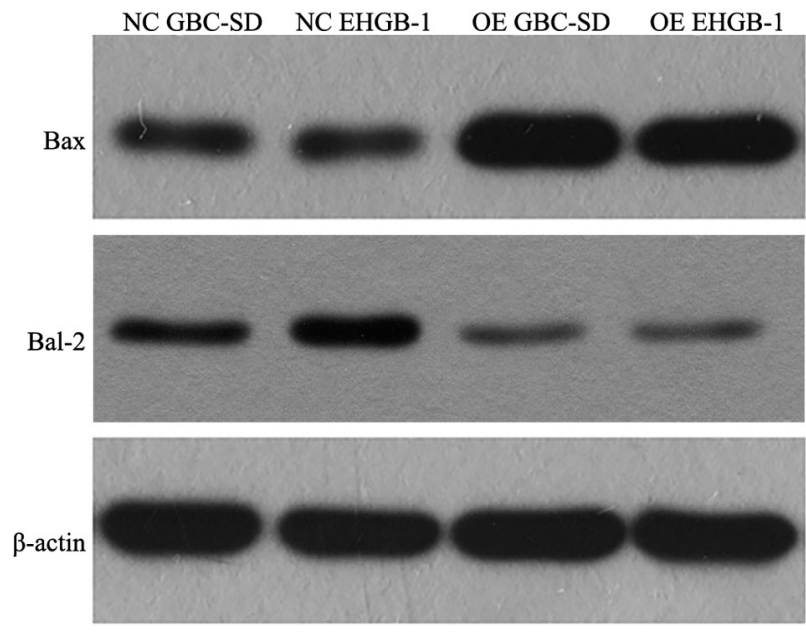

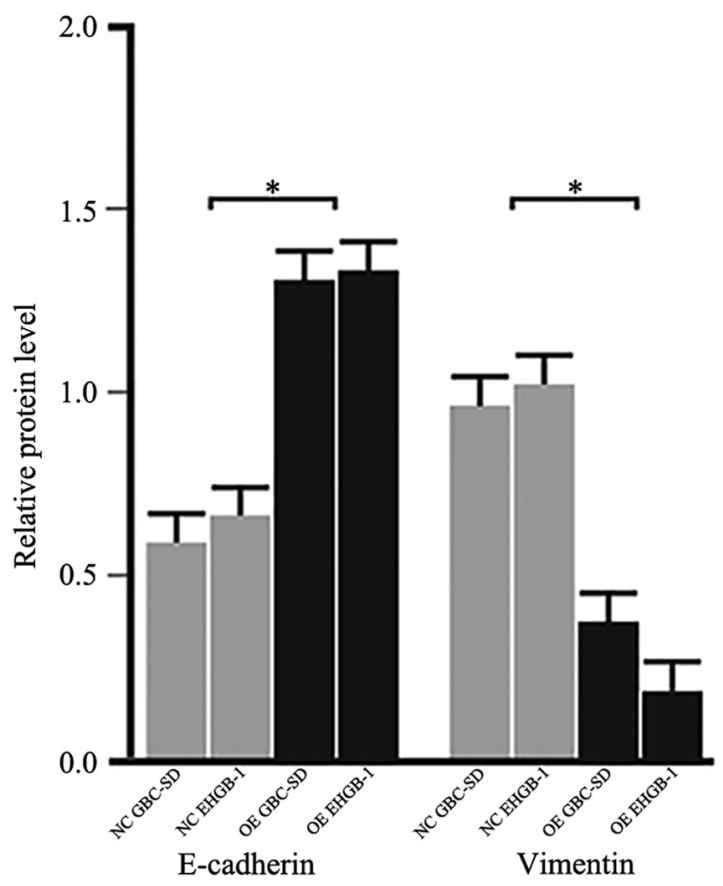

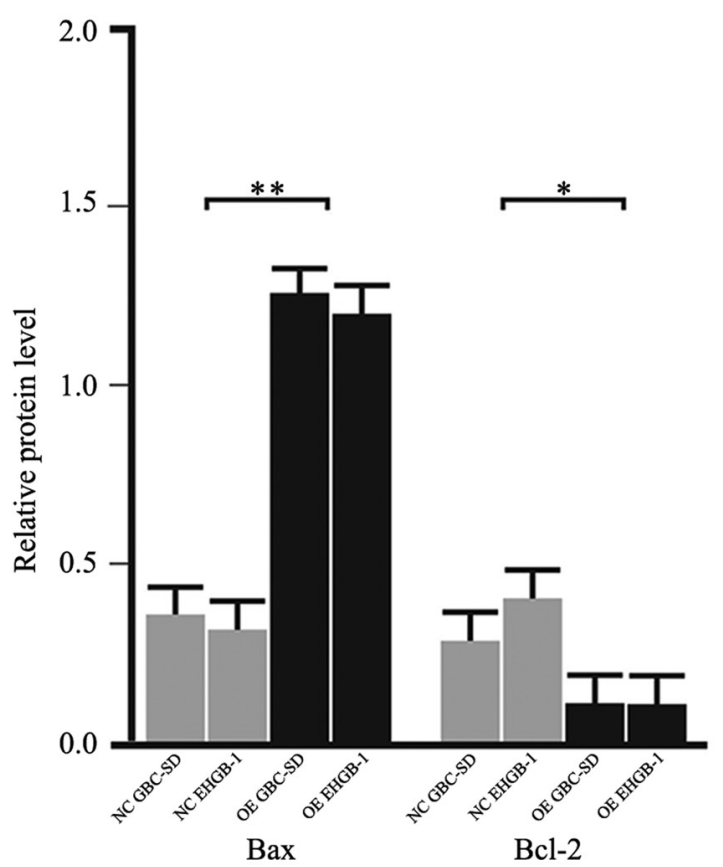

Figure 4. PUMA overexpression regulates the expression of proteins associated with the epithelial-mesenchymal transition and apoptosis. (A) The protein levels of E-cadherin were upregulated, whereas the levels of vimentin were downregulated in the GBC-SD and EHGB-1 OE groups compared with those in the corresponding NC groups. (B) The protein expression levels of Bax were upregulated, whereas the expression levels of Bcl-2 were downregulated in the GBC-SD and EHGB-1 OE groups compared with those in the $\mathrm{NC}$ groups. ${ }^{*} \mathrm{P}<0.05$ and ${ }^{* * *} \mathrm{P}<0.01$. PUMA, p53-upregulated modulator of apoptosis; NC, negative control; OE, PUMA overexpression.

EHGB-1 cells were detected by flow cytometry. As demonstrated in Fig. 5, the apoptotic rates were 5.0 \pm 1.7 and 5.4 $\pm 1.8 \%$ in the GBC-SD and EHGB-1 control groups, respectively, but sharply increased to $35.0 \pm 4.5$ and $28.6 \pm 3.9 \%$ in the GBC-SD and EHGB-1 PUMA overexpression groups, respectively (both $\mathrm{P}<0.01$ ).

PUMA is a predictor of a favorable prognosis in patients with $G B C$. Patients with GBC included in the present study were followed up. According to the relative PUMA mRNA expression level and the logarithm of $2^{-\Delta \Delta \mathrm{Ct}}$ value was zero as a cutoff point, the patients were divided into PUMA high $(n=4)$ and low $(n=14)$ groups. No deaths occurred in the two groups in first three months after surgery. As demonstrated in Fig. 6, patients in the PUMA high group exhibited a longer overall survival time compared with those in the PUMA low group $(\mathrm{P}<0.05)$.

\section{Discussion}

Emerging evidence has suggested that alterations in a number of tumor-suppressor genes and oncogenes are associated with 
A
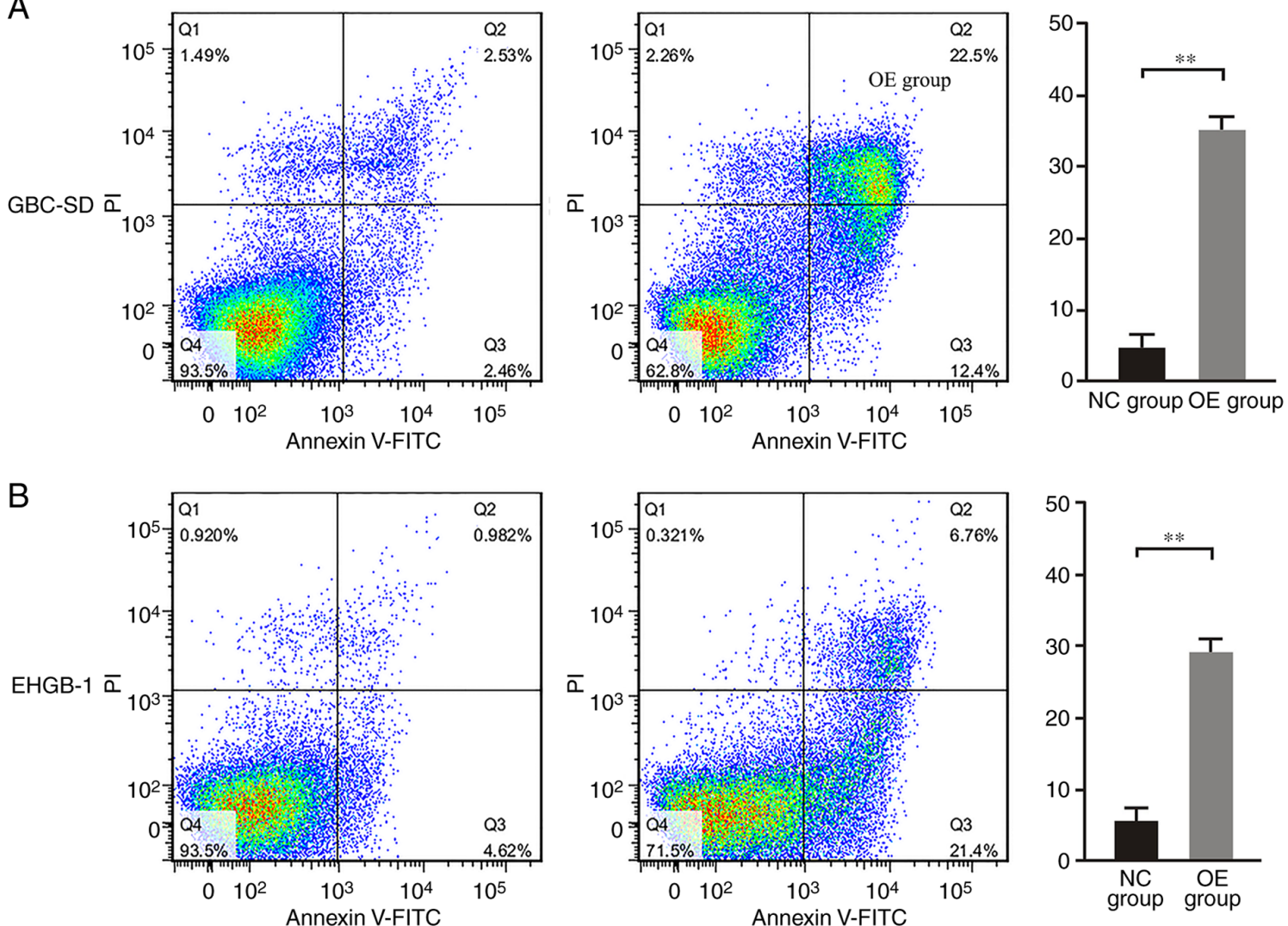

Figure 5. PUMA inhibits apoptosis in gallbladder carcinoma cells. The apoptotic rates were significantly higher in the (A) GBC-SD and (B) EHGB-1 OE groups compared with those in the NC groups. ${ }^{* *} \mathrm{P}<0.01$. PUMA, p53-upregulated modulator of apoptosis; NC, negative control; OE, PUMA overexpression.

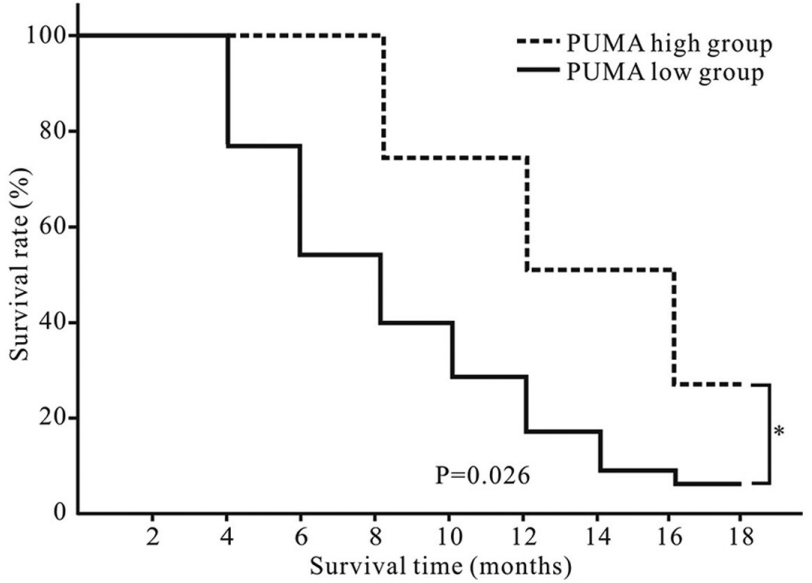

Figure 6. PUMA is associated with survival in patients with gallbladder carcinoma. Patients in the PUMA high group presented with a longer overall survival time compared with those in the PUMA low group. ${ }^{*} \mathrm{P}<0.05$. PUMA, p53-upregulated modulator of apoptosis.

the oncogenesis and progression of $\operatorname{GBC}(17,18)$; however, the specific molecular mechanism of GBC remains largely unclear. Due to the poor prognosis of patients with GBC, it is necessary to urgently identify the exact mechanisms of occurrence and progression of GBC.

Previous studies have reported that PUMA induces apoptosis in normal and tumor cells (19-22); however, a limited number of studies are currently available on the role of PUMA in GBC (23-25). Our previous study has demonstrated the expression of PUMA and its pathological significance in GBC, adjacent tissues, adenomatous gallbladder polyps and chronic cholecystitis (23). Another study has investigated the expression of PUMA and its clinicopathological significance in benign and malignant lesions of the gallbladder, concluding that PUMA is associated with the carcinogenesis, progression, metastasis and high invasiveness of gallbladder adenocarcinoma (24). Additionally, the expression of WW domain-containing oxidoreductase and its effects on inducing apoptosis by upregulating the expression of PUMA in GBC cells have been demonstrated (25). However, in the three aforementioned studies, the expression levels of PUMA in GBC cell lines have not been reported. In the present study, the expression levels of PUMA in GBC, adjacent tissues and GBC cell lines were investigated, and a series of functional experiments were performed to study the effects of PUMA on GBC for the first time.

The biological functions of the PUMA gene have been introduced in detail in a previous study (23). The p53dependent and non-dependent apoptotic pathways serve key roles in PUMA-induced apoptosis; previous studies have reported that the mechanism of PUMA-induced apoptosis may include the following: i) PUMA and $\mathrm{Bcl}-2 / \mathrm{Bcl} 2 \mathrm{xl}$ combine to inhibit the Bax/Bak signaling pathway in normal or tumor cells (9); ii) PUMA combines with $\mathrm{p} 53 / \mathrm{Bcl} 2 \times 1$ to release $\mathrm{p} 53$, which activates Bax to induce apoptosis $(9,20,21)$; iii) PUMA directly binds to Bax/Bak to change its conformational, and then Bax is activated to induce cell apoptosis $(21,22)$. However, 
further studies are needed to elucidate the precise underlying mechanism of PUMA-induced apoptosis.

Our previous study has reported that PUMA is a marker that may be associated with the clinical behavior of GBC and may reflect the occurrence, development and prognosis of GBC in patient tissues (23). In the present study, the expression levels of PUMA were detected in GBC tissues and cell lines, and its functional roles on the biological behaviors of GBC cell lines were further investigated. The results demonstrated that the expression levels of PUMA were significantly lower in GBC tissues compared with those in the adjacent tissues, and were low in GBC cell lines. Further experiments were performed in vitro to demonstrate the functions of PUMA in the biological behavior of GBC; the results demonstrated that following overexpression, PUMA significantly inhibited the proliferative and invasive abilities of GBC cells compared with those of the control groups, which suggested that PUMA may serve as a tumor suppressor in GBC.

The potential mechanisms of PUMA-inhibited invasion were further investigated in the present study. The EMT is a process during which epithelial cells trans-differentiate into mesenchymal cells $(26,27)$. The EMT endows tumor cells with the traits of migration and invasion and induces cancer stem cell properties $(27,28)$. However, the effects of the EMT in PUMA-induced GBC cell apoptosis remain unknown. The results of the present study demonstrated that PUMA overexpression in GBC cell lines increased the protein expression levels of E-cadherin and decreased the levels of vimentin compared with those in the negative control group. These results suggested that PUMA-induced EMT reversal may account for the inhibitory effects of PUMA on GBC cell invasion. However, further studies are needed to unravel the precise signaling pathways involved in the PUMA-mediated inhibition of the EMT.

The results of the present study also demonstrated that the protein expression levels of Bax were upregulated, whereas the levels of Bcl-2 were downregulated following PUMA overexpression compared with those in the negative control groups. The Bcl-2 family serves a vital role in apoptosis (29). As a member of the Bcl-2 family, Bax promotes apoptosis; the protein expression levels of Bax are associated with the regulation of apoptosis, since high levels of the Bax protein induce apoptosis $(30,31)$. As a suppressor of apoptosis, Bcl-2 negatively regulates apoptosis by regulating mitochondrial cytochrome $c$ release (32). In addition, $\mathrm{Bcl}-2$ binds to Bax to form a Bax/Bcl-2 polymer to inhibit the apoptotic process (33). High expression levels of Bcl-2 also maintain cell stability by inducing glutathione aggregation in the cell nucleus to reduce caspase activity (34). The results of the present study suggested that PUMA may inhibit GBC invasion at least partially by regulating the expression of Bax and Bcl-2. However, further studies are needed to clarify the exact mechanism of this regulation process.

In the present study, a normal gallbladder epithelial cell line was intended to be used as a control for the in vitro experiments; however, careful review of the available literature did not identify any normal gallbladder epithelial cell lines. Primary culture of cells isolated from normal gallbladder wall tissues were subsequently considered. However, these cells could not be used as a control cell line due to their short survival time.
The follow-up results in the present study demonstrated that patients with GBC in the PUMA high group exhibited a longer survival time compared with those in the PUMA low group, which suggested that PUMA may be a new clinical marker for the prognosis of GBC and may serve as a potential target for the diagnosis and treatment of patients with GBC. However, a larger sample and long-term studies are required to verify this hypothesis.

In the present study, the expression levels of PUMA and its inhibitory effects on GBC were only investigated by a limited number of clinical specimen and cell experiments. Further studies are required to confirm these results in a large sample and in vivo animal experiments.

In conclusion, the results of the present study demonstrated that PUMA inhibited the proliferative and invasive capabilities of GBC cells through the $\mathrm{Bax} / \mathrm{Bcl}-2$ signaling pathway and partially by regulating the EMT. These results suggested that PUMA may serve as a potential tumor maker for the diagnosis and treatment of GBC in clinical practice. In the last decade, studies on circulating tumor cells (CTCs) have enriched the methods of detecting tumor cells $(35,36)$; in our future work, the potential functions of PUMA in CTCs will be investigated.

\section{Acknowledgements}

Not applicable.

\section{Funding}

This work was supported by the National Natural Science Foundation of China, Beijing (grant no. 81703767 to WC) and the Hunan Natural Science Foundation of China, Changsha (grant no. 2019JJ50891 to WC).

\section{Availability of data and materials}

The datasets used and/or analyzed during the current study are available from the corresponding author on reasonable request.

\section{Authors' contributions}

QL and WC conceived and designed the study. ZL and CY obtained the clinical samples and were the major contributors in acquiring the data. WZ and LW performed the cell experiments. WC and YX analyzed and interpreted the data, and drafted the manuscript. QL and WC revised the manuscript. $\mathrm{ZL}$ and WC confirm the authenticity of all the raw data. All authors read and approved the final manuscript.

\section{Ethics approval and consent to participate}

This study was approved by the Research Ethics Committee of Second Xiangya Hospital (approval no. 179 in 2017; Changsha, China). Informed consent was obtained from all included patients.

\section{Patient consent for publication}

Not applicable. 


\section{Competing interests}

The authors declare that they have no competing interests.

\section{References}

1. Kanthan R, Senger JL, Ahmed S and Kanthan SC: Gallbladder Cancer in the 21st Century. J Oncol 2015: 967472, 2015.

2. Jiahong D, Jianming $\mathrm{W}$ and Jianping Z: Guidelines for diagnosis and treatment of gallbladder cancer (2015 edition). J Clin Hepatol 32: 411-419, 2015.

3. Kakaei F, Beheshtirouy S, Nejatollahi SM, Zarrintan S and Mafi MR: Surgical treatment of gallbladder carcinoma: A critical review. Updates Surg 67: 339-351, 2015.

4. Cziupka K, Partecke LI, Mirow L, Heidecke CD, Emde C, Hoffmann W, Siewert U, van den Berg N, von Bernstorff W and Stier A: Outcomes and prognostic factors in gallbladder cancer: A single-centre experience. Langenbecks Arch Surg 397: 899-907, 2012.

5. Lazcano-Ponce EC, Miquel JF, Muñoz N, Herrero R, Ferrecio C, Wistuba II, Alonso de Ruiz P, Aristi Urista G and Nervi F: Epidemiology and molecular pathology of gallbladder cancer. CA Cancer J Clin 51: 349-364, 2001.

6. Mekeel KL and Hemming AW: Surgical management of gallbladder carcinoma: A review. J Gastrointest Surg 11: 1188-1193, 2007.

7. Zhang LF, Hou CS, Xu Z, Guo LM, Ling XF, Wang LX and Xiu DR: Laparoscopic treatment for incidental gallbladder cancer: A retrospective 10 years study from a single institution. Zhonghua Wai Ke Za Zhi 57: 277-281, 2019 (In Chinese).

8. Butte JM, Matsuo K, Gönen M, D'Angelica MI, Waugh E, Allen PJ, Fong Y, DeMatteo RP, Blumgart L, Endo I, et al: Gallbladder cancer: Differences in presentation, surgical treatment, and survival in patients treated at centers in three countries. J Am Coll Surg 212: 50-61, 2011.

9. Yu J: PUMA kills stem cells to stall cancer? Mol Cell Pharmacol 1: 112-118, 2009.

10. Yu J, Wang Z, Kinzler KW, Vogelstein B and Zhang L: PUMA mediates the apoptotic response to p53 in colorectal cancer cells. Proc Natl Acad Sci USA 100: 1931-1936, 2003.

11. He S, Ma X, Ye Y, Zhang M, Zhuang J, Song Y and Xia W: HEATR1 modulates cell survival in non-small cell lung cancer via activation of the p53/PUMA signaling pathway. Onco Targets Ther 12: 4001-4011, 2019.

12. Yee KS, Wilkinson S, James J, Ryan KM and Vousden KH: PUMA- and Bax-induced autophagy contributes to apoptosis. Cell Death Differ 16: 1135-1145, 2009.

13. Sinicrope FA, Rego RL, Okumura K, Foster NR, O'Connell MJ, Sargent DJ and Windschitl HE: Prognostic impact of bim, puma, and noxa expression in human colon carcinomas. Clin Cancer Res 14: 5810-5818, 2008

14. Diallo JS, Aldejmah A, Mouhim AF, Péant B, Fahmy MA, Koumakpayi IH, Sircar K, Bégin LR, Mes-Masson AM and Saad F: NOXA and PUMA expression add to clinical markers in predicting biochemical recurrence of prostate cancer patients in a survival tree model. Clin Cancer Res 13: 7044-7052, 2007.

15. Nevin JE, Moran TJ, Kay S and King R: Carcinoma of the gallbladder: Staging, treatment, and prognosis. Cancer 37: 141-148, 1976.

16. Livak KJ and Schmittgen TD: Analysis of relative gene expression data using real-time quantitative PCR and the 2(-Delta Delta C(T)) method. Methods 25: 402-408, 2001.

17. Sharma A, Kumar A, Kumari N, Krishnani N and Rastogi N: Mutational frequency of KRAS, NRAS, IDH2, PIK3CA, and EGFR in North Indian gallbladder cancer patients Ecancermedicalscience 11: 757, 2017.

18. Kim YW, Huh SH, Park YK, Yoon TY, Lee SM and Hong SM: Expression of the c-erb-B2 and p53 protein in gallbladder carcinomas. Oncol Rep 8: 1127-1132, 2001.

19. Niizuma K, Endo H, Nito C, Myer DJ and Chan PH: Potential role of PUMA in delayed death of hippocampal CA1 neurons after transient global cerebral ischemia. Stroke 40: 618-625, 2009 .
20. Sun YL, Jiang WQ, Luo QY, Yang DJ, Cai YC, Huang HQ and Sun J: A novel Bcl-2 inhibitor, BM-1197, induces apoptosis in malignant lymphoma cells through the endogenous apoptotic pathway. BMC Cancer 20: 1, 2019.

21. Letai A: Puma strikes Bax. J Cell Biol 185: 189-191, 2009.

22. Erlacher M, Labi V, Manzl C, Böck G, Tzankov A, Häcker G, Michalak E, Strasser A and Villunger A: Puma cooperates with $\mathrm{Bim}$, the rate-limiting $\mathrm{BH} 3$-only protein in cell death during lymphocyte development, in apoptosis induction. J Exp Med 203: 2939-2951, 2006.

23. Cai W, Li Q, Yang Z, Miao X, Wen Y, Huang S and Ouyang J: Expression of p53 upregulated modulator of apoptosis (PUMA) and C-myb in gallbladder adenocarcinoma and their pathological significance. Clin Transl Oncol 15: 818-824, 2013.

24. Shu GS, Lv F, Yang ZL and Miao XY: Immunohistochemical study of PUMA, c-Myb and p53 expression in the benign and malignant lesions of gallbladder and their clinicopathological significances. Int J Clin Oncol 18: 641-650, 2013.

25. Wei D, Zhang X, Zou H, Wang L, Fu B, Wu X, Luo Z, Li X, Ge J, Li Y, et al: WW domain containing oxidoreductase induces apoptosis in gallbladder-derived malignant cell by upregulating expression of P73 and PUMA. Tumour Biol 35: 1539-1550, 2014

26. Thiery JP, Acloque H, Huang RY and Nieto MA: Epithelial-mesenchymal transitions in development and desease. Cell 139: 871-890, 2009.

27. Fu XT, Dai Z, Song K, Zhang ZJ, Zhou ZJ, Zhou SL, Zhao YM, Xiao YS, Sun QM, Ding ZB and Fan J: Macrophage-secreted IL-8 induces epithelial-mesenchymal transition in hepatocellular carcinoma cells by activating the JAK2/STAT3/Snail pathway. Int J Oncol 46: 587-596, 2015.

28. Mani SA, Guo W, Liao MJ, Eaton EN, Ayyanan A, Zhou AY, Brooks M, Reinhard F, Zhang CC, Shipitsin M, et al: The epithelial-mesenchymal transition generates cells with properties of stem cells. Cell 133: 704-715, 2008

29. Babu PP, Suzuki G, Ono Y and Yoshida Y: Attenuation of ischemia and/or reperfusion injury during myocardial infarction using mild hypothermia in rats: An immunohistochemical study of bcl-2, bax, Bak and TUNEL. Pathol Int 54: 896-903, 2004.

30. Duan XX, Ou JS, Li Y, Su JJ, Ou C, Yang C, Yue HF and Ban KC: Dynamic expression of apoptosis related genes during development of laboratory hepatocellular carcinoma and its relation to apoptosis. World J Gastroenterol 11: 4740-4744, 2005.

31. Martin LJ: Neuronal cell death in nervous system development, disease, and injury (Review). Int J Mol Med 7: 455-478, 2001

32. Cecconi F, Alvarez-Bolado G, Meyer BI, Roth KA and Gruss P: Apaf1 (CED-4 homolog) regulates programmed cell death in mammalian development. Cell 94: 727-737, 1998.

33. McDonnell TJ, Troncoso P, Brisbay SM, Logothetis C, Chung LW, Hsieh JT, Tu SM and Campbell ML: Expression of the protooncogene $\mathrm{Bcl}-2$ in the prostate and its association with emergence of androgen-independent prostate cancer. Cancer Res 52: 6940-6944, 1992.

34. Roos A, Sato T, Maier H, van Kooten C and Daha MR: Induction of renal cell apoptosis by antibodies and compiement. Exp Nephrol 9: 65-70, 2001.

35. Fan ZC, Yan J, Liu GD, Tan XY, Weng XF, Wu WZ, Zhou J and Wei XB: Real-time monitoring of rare circulating hepatocelluar carcinoma cells in an orthotopic model by in vivo flow cytometry assesses resection on metastasis. Cancer Res 72: 2683-2691, 2012.

36. Yan J, Fan Z, Wu X, Xu M, Jiang J, Tan C, Wu W, Wei X and Zhou J: Circulating tumor cells are correlated with disease progression and treatment response in an orthotopic hepatocellular carcinoma model. Cytometry A 87: 1020-1028, 2015.

This work is licensed under a Creative Commons Attribution-NonCommercial-NoDerivatives 4.0 International (CC BY-NC-ND 4.0) License. 